\title{
Body mass index and physical activity in early childhood are associated with atopic sensitization, atopic dermatitis and asthma in later childhood
}

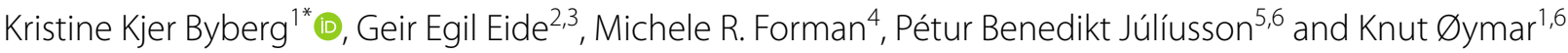

\begin{abstract}
Background: The results of studies on the associations of childhood excessive weight/obesity and physical activity with atopic sensitization and atopic diseases are inconsistent. We studied the associations of anthropometry and physical activity in childhood with atopic sensitization and atopic diseases in late childhood.

Methods: In a cohort study including cases exposed to preeclampsia during pregnancy and controls, anthropometry and physical activity were assessed at several ages in 617 children. Associations with atopic sensitization and atopic diseases in late childhood were analysed using multiple logistic regression.

Results: Body mass index standard deviation score (BMI SDS) at 1 year and low physical activity at 3-6 years were positively associated with atopic sensitization at 12.8 years [adjusted odds ratio (OR) 1.22; $95 \%$ confidence interval $(1.00,1.49)$ and OR 2.36; $(1.15,4.81)$, respectively]. Change in BMI SDS from 1 to 4 years, BMI SDS at 4 years, and high physical activity at $6-10$ years were positively associated with atopic dermatitis by 10.8 years [OR $1.46 ;(1.11,1.92)$; OR 1.32; $(1.06,1.65)$ and OR 1.94; $(1.16,3.24)$; respectively]. Low physical activity at $3-6$ and $6-10$ years were positively associated with asthma by 10.8 years [OR $3.61 ;(1.56,8.36)$ and OR 2.52; $(1.24,5.12)$, respectively].
\end{abstract}

Conclusions: BMI and physical activity in early childhood were associated with atopic sensitization, atopic dermatitis and asthma in later childhood. Larger cohorts with repeated measurements of both predictors and outcomes are required to further elucidate this issue.

Trial registration Our study was observational without any clinical intervention on the participants. Therefore, no trial registration number is available

Keywords: Allergic rhinitis, Anthropometry, Asthma, Atopic dermatitis, Child

\section{Background}

The prevalence of obesity, allergy and asthma has increased worldwide during the last decades $[1,2]$. An association between obesity and asthma has been suggested both in early and late childhood [3], where obesity precedes asthma in prospective studies [4]; the association between obesity and allergy is inconsistent [5].

*Correspondence: Kristine.kjer.byberg@sus.no

1 Department of Pediatrics, Stavanger University Hospital, POB 8100,

4068 Stavanger, Norway

Full list of author information is available at the end of the article
High birth weight or body mass index (BMI; $\mathrm{kg} / \mathrm{m}^{2}$ ) in early childhood is associated with obesity into later childhood [6]. Atopic sensitization and atopic disease commonly start in early childhood [7], and associations between accelerated weight gain in early childhood and subsequent atopic sensitization, allergic rhinitis [8] and asthma [9], have been suggested, but not for atopic dermatitis. Physical activity during childhood may also be associated with atopy, either directly or due to an influence on body composition [10].

Many of these associations of childhood obesity and physical activity with atopy appear in cross-sectional 
studies $[5,10,11]$. Few longitudinal studies exist, mainly from registers $[4,5,11]$.

It is unknown if an accelerated weight gain from birth is associated with an increased risk of atopy. Furthermore, it is unknown if a positive association between BMI and asthma in children is limited to those with atopy.

The present cohort study was derived from a case control study nested within three birth cohorts that focused on preeclampsia, that had repeated anthropometric measurements, linked information across childhood, and measures of atopic disease at clinical follow-ups. The aim was to study whether weight-related anthropometrics, changes in BMI SDS and physical activity at different ages in childhood are associated with atopic sensitization and atopic disease by late childhood. We hypothesized that childhood excessive weight/obesity or accelerated weight gain is positively associated and physical activity negatively associated with atopic sensitization and atopic diseases.

\section{Methods}

\section{Study population and design}

The study was a part of "the Stavanger study" described in detail previously [12]. From a population-based cohort, a nested case-control study was conducted, where offspring exposed to maternal preeclampsia and unexposed offspring were identified from all births delivered in Stavanger University hospital in 1993-1995. For each exposed offspring, two matched unexposed offspring were selected: one as the next born in the hospital (i.e. a birth match) and one as the next born matched on maternal age (i.e. a risk factor for preeclampsia). 1025 children, 366 in the preeclampsia and 659 in the control group, were invited to participate in a first followup study at 10.8 years (girls) and 11.8 years (boys), and a second follow-up at 12.8 years (both sexes) [13]. The ages at follow-up were selected to coincide with the ages of pubertal onset and menarche of the children. Our analyses disregarded the matched pairs due to missing participants. Therefore, in our study, data were analysed as a historical cohort adjusting for preeclampsia and maternal age, including all the children who participated in both follow-ups, with predictors as listed.

The study was approved by the Norwegian Data Inspectorate, the Regional Committee for Ethics in medical research Western Norway, and the Institutional Review Boards of the National Cancer Institute and University of Texas at Austin, United States. Mothers and children signed an informed consent/assent form at follow-up.

\section{Outcomes}

The outcomes allergic rhinoconjunctivitis, atopic dermatitis, asthma ever (evaluated at first follow-up), atopic sensitization and current asthma (evaluated at second follow-up) were defined as follows:

Atopic sensitization Blood specific immunoglobulin $\mathrm{E}(\mathrm{IgE}) \geq 0.35 \mathrm{kU} / \mathrm{l}$ for at least one common allergen. Blood was drawn at second follow-up and analysed by Phadiatop ${ }^{\circledR}, \mathrm{f}_{\mathrm{x}} 5 \mathrm{E}^{\circledR}$ and by specific IgE when positive [13]. Included allergens are shown in Fig. 1. The levels of specific IgE $\geq 0.35$ were added, and high grade sensitization was defined as a sum $>3.9 \mathrm{kU} / \mathrm{l}$ : above the lower quartile of all children being sensitized. The ordinal outcome variable atopic sensitization was categorized as: no, low grade and high grade sensitization.

Atopic disease: Asthma ever, allergic rhinoconjunctivitis or atopic dermatitis At first follow-up, questions on atopic disease of the child were asked to the mothers: "Has your child ever had doctor-diagnosed asthma or ever diagnosed with allergy in nose/eyes (hay fever) or atopic dermatitis (childhood eczema)?" Response of "yes" was classified as having the respective diagnosis.

Current asthma At second follow-up, the children answered a questionnaire on reported asthma symptoms and medication during the last year according to the International Study of Asthma and Allergies in Childhood (ISAAC) and asthma ever was recorded [14]. Current asthma at second follow-up was defined as asthma ever, in addition to asthma symptoms or the use of asthma medication the last 12 months (Additional file 1).

\section{Predictors}

Birthweight and gestational age were abstracted from hospital records. Recordings of length/height and weight measurements were collected from well-baby clinics at the target ages of 3, 6 and 12 months and 4 years. Trained nurse researchers measured height, weight, triceps skinfold and waist circumference twice in offspring at both

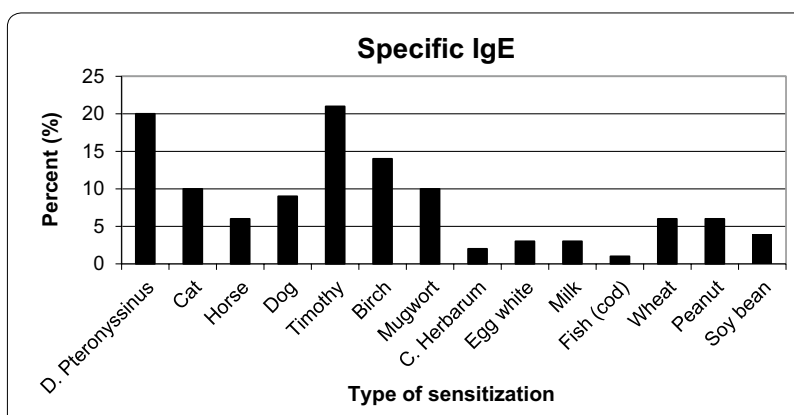

Fig. 1 Percent of children with sensitization (specific lgE $>0.35 \mathrm{kU} / \mathrm{l}$ ) to common allergens, measured at 12.8 years $(n=388)$. D: dermatophagoides, C: cladosporium 
follow-ups, and subscapular skinfold was measured twice at second follow-up; the average of each was used in the analysis [12]. Skinfolds were measured with Harpenden Skinfold Calliper ${ }^{\circledR}$.

Change in weight and BMI SDS was calculated as the difference between weight and BMI SDS from each target age to the next.

At the first follow-up, the "Stanford Brief Activity Survey", a questionnaire validated for adults, was administered to the mothers requesting responses about physical activity of the child. Specifically the answers to the following questions were extracted: "How active was your child at 3-6 years?" and "How active was your child at 6-10 years?" The response categories were categorized as: passive and/or not so active $=$ low activity, active $=$ normal, very active $=$ high activity [15] .

\section{Confounders}

Potential confounders included categorical and continuous variables, i.e. sex; gestational age; birth order (firstborn or not); duration of breastfeeding (categories: none; $<3$; $>3$ months. This information was extracted from maternal questionnaire, and used in analyses for predictors at target ages $\geq 6$ months); mother's preeclampsia (none, mild/moderate, severe) [16]; mother's BMI (weight at first antenatal visit and height at first followup); mother's smoking (at first antenatal visit); mother's doctor-diagnosed asthma [13]; mother's education (from maternal questionnaire: $\langle 9 ; 9-12$; $>12$ years) and mother's age. This is illustrated in a Directed Acyclic Graph (Additional file 1: Figure S1) [17].

\section{Statistical methods}

Descriptive statistics were analysed as means, standard deviations, numbers and percentages for the main predictors and outcomes.

There was a wide range of gestational ages at birth due to the inclusion of offspring of preeclampsia and normotensives and a wide age range at later well-child visits, analysing actual values for anthropometrics as predictors would therefore not be appropriate. Instead, standard deviation scores (SDS) based on anthropometric values and actual ages were computed from validated references [18-21]. Conversions into SDS were done using $\mathrm{R}$ version 2.6.2 (R Development Core Team, Vienna, Austria).

The associations between anthropometrics and physical activity for each target age (see predictors), and outcomes of atopic sensitization and atopic diseases in late childhood were analysed using multiple binary and ordinal logistic regression analyses (the latter for outcome of atopic sensitization). Separate analyses of the predictors were done for each follow-up time.
Each variable was entered separately into simple regression models. Next, all potential confounders were included in fully adjusted models. Backward stepwise selections were performed to remove non-significant confounders, unless there was $\geq 15 \%$ change in effect size upon removal of the confounder. Last, final models for each target age included anthropometrics, physical activity, sex of the child and all remaining confounders.

For each predictor, odds ratios with p-values from likelihood ratio tests and $95 \%$ confidence intervals are reported. Interactions between anthropometrics and physical activity with potential confounders were tested. The significance level was 0.05 for all tests.

Also, to study possible non-straight-line associations between BMI SDS and the outcomes, multiple fractional polynomial regression (MFPR) was used with the conservative requirement of $\mathrm{p} \leq 0.01$ for non-straight-line terms.

Due to missing values the number of participants varied between the different analyses.

IBM SPSS for windows (version 22.0.0, Chicago, Ill., USA) was used for descriptive statistics and logistic regression, and Stata SE 14 for MFPR.

\section{Results}

\section{Characteristics of the participants}

The numbers of participants in each follow-up have been published previously [13]. Briefly, 617 children assented to participate at the first follow-up and 470 at the second follow-up. There were more girls with high BMI in the first than second follow-up, and more children with atopic dermatitis in the first than the second follow-up. Otherwise, baseline characteristics were similar between those who assented to the first follow-up only and those who assented to both follow-ups [13]. The percentages of children sensitized to different allergens appear in Fig. 1. Clinical characteristics of the participants appear in Table 1.

\section{Impact of anthropometrics (Tables 2, 3, 4)}

BMI SDS at 1 year was positively associated with atopic sensitization at 12.8 years with a borderline significance (Table 2). Change in BMI SDS from 1 to 4 years and BMI SDS at 4 years were positively associated with atopic dermatitis ever at the first follow-up (Tables 2, 3).

Birthweight/BMI SDS and changes in weight or BMI SDS were not associated with allergic rhinoconjunctivitis (Tables 2, 3) or asthma (Table 4 and Additional file 2: Table S1). Skinfolds, waist circumference and waist-to-height ratio at the follow-ups were not associated with atopic sensitization or atopic disease (Additional file 2: Table S2). 
Table 1 Descriptive statistics for predictors and outcomes for $617^{\mathrm{a}}$ children included in a matched cohort study with follow-up from birth to 12-13 years in the Stavanger area, Norway

\begin{tabular}{|c|c|c|c|}
\hline Predictors & $\mathrm{n}$ & Mean & SD \\
\hline Birthweight (kg) & 606 & 3.37 & 0.71 \\
\hline BMI 3 months & 541 & 16.4 & 1.52 \\
\hline BMI 6 months & 559 & 17.2 & 1.53 \\
\hline BMl 1 year & 559 & 17.2 & 1.49 \\
\hline BMI 4 years & 477 & 15.9 & 1.43 \\
\hline BMI first follow-up ${ }^{b}$ & 610 & 18.0 & 2.91 \\
\hline BMI second follow-up ${ }^{c}$ & 466 & 18.8 & 3.00 \\
\hline Waist circumference (cm) first follow-up & 610 & 63.5 & 7.80 \\
\hline Waist circumference $(\mathrm{cm})$ second follow-up & 466 & 68.0 & 7.72 \\
\hline Triceps skinfold (mm) first follow-up & 605 & 11.7 & 4.63 \\
\hline Triceps skinfold (mm) second follow-up & 465 & 12.1 & 4.81 \\
\hline Waist-to-height ratio first follow-up & 610 & 0.42 & 0.04 \\
\hline Waist-to-height ratio second follow-up & 466 & 0.43 & 0.05 \\
\hline \multirow[t]{2}{*}{ Subscapular skinfold (mm) second follow-up } & 450 & 8.21 & 3.24 \\
\hline & \multicolumn{2}{|r|}{$\mathbf{n}$} & $\%$ \\
\hline Physical activity 3-6 years & \multicolumn{2}{|r|}{601} & \\
\hline Low & \multicolumn{2}{|r|}{72} & 12 \\
\hline Normal & \multicolumn{2}{|r|}{370} & 62 \\
\hline High & \multicolumn{2}{|r|}{159} & 26 \\
\hline Physical activity $6-10$ years & \multicolumn{2}{|r|}{596} & \\
\hline Low & \multicolumn{2}{|r|}{99} & 17 \\
\hline Normal & \multicolumn{2}{|r|}{376} & 63 \\
\hline High & \multicolumn{2}{|r|}{121} & 20 \\
\hline \multicolumn{4}{|l|}{ Outcome } \\
\hline Atopic sensitization at second follow-up ${ }^{d}$ & \multicolumn{2}{|r|}{$133 / 388$} & 34 \\
\hline Allergic rhinoconjunctivitis ever by first follow-up & \multicolumn{2}{|r|}{$131 / 595$} & 22 \\
\hline Atopic dermatitis ever by first follow-up & \multicolumn{2}{|r|}{$149 / 596$} & 25 \\
\hline Asthma ever by first follow-up & \multicolumn{2}{|r|}{$53 / 590$} & 9 \\
\hline Current asthma at second follow-up & \multicolumn{2}{|r|}{$37 / 458$} & 8 \\
\hline
\end{tabular}

$S D$ standard deviation, $B M /$ body mass index $\left(\mathrm{kg} / \mathrm{m}^{2}\right)$

a Due to missing values and variation in response, the number of participants varied between the different predictors and outcomes

b First follow-up: 10.8 years (girls), 11.8 years (boys)

c Second follow-up: 12.8 years

d 99 (25.5 \%) had high grade atopic sensitization (sum of specific $\lg \mathrm{E} \geq 3.9 \mathrm{kU} / \mathrm{l}$ )

\section{Impact of physical activity (Tables 2, 4)}

Low physical activity at 3-6 years was positively associated with atopic sensitization at 12.8 years (Table 2 ). High physical activity at $6-10$ years was positively associated with atopic dermatitis ever at the first follow-up (Table 2). Low physical activity at 3-6 and 6-10 years were positively associated with asthma ever at the first follow-up (Table 4). Physical activity was not associated with allergic rhinoconjunctivitis.
In the MFPR analyses, no non-straight-line associations were found for anthropometrics or physical activity with atopic sensitization or atopic diseases (data not shown).

\section{Discussion}

In this cohort study of children followed from birth to 12.8 years, after adjusting for potential confounders, BMI in childhood was positively associated with atopic sensitization and atopic dermatitis in late childhood. High and 
Table 2 The adjusted odds ratios of atopic sensitization and atopic disease in adolescence in 617 Norwegian children by weight/BMI SDS and physical activity after backward stepwise selection of potential confounders (one model for each predictor variable)

\begin{tabular}{|c|c|c|c|c|c|c|c|c|c|c|c|c|}
\hline \multirow{3}{*}{$\begin{array}{l}\text { Predictor } \\
\text { Age }\end{array}$} & \multicolumn{12}{|c|}{ Outcome variable (final analyses) } \\
\hline & \multicolumn{4}{|c|}{ Atopic sensitization ${ }^{\mathrm{a}, \mathrm{b}}$} & \multicolumn{4}{|c|}{ Allergic rhinoconjunctivitis ${ }^{a}$} & \multicolumn{4}{|c|}{ Atopic dermatitis ${ }^{c}$} \\
\hline & $\mathrm{n}$ & OR & $95 \% \mathrm{Cl}$ & LR-p & $\mathrm{n}$ & OR & $95 \% \mathrm{Cl}$ & LR-p & $\mathrm{n}$ & OR & $95 \% \mathrm{Cl}$ & LR-p \\
\hline \multicolumn{13}{|l|}{ Weight SDS } \\
\hline Birth & 380 & 1.05 & $(0.87,1.26)$ & 0.609 & 580 & 0.92 & $(0.77,1.10)$ & 0.338 & 544 & 1.04 & $(0.88,1.22)$ & 0.638 \\
\hline \multicolumn{13}{|l|}{ BMISDS } \\
\hline 3 months & 353 & 1.13 & $(0.90,1.41)$ & 0.315 & 521 & 0.91 & $(0.73,1.14)$ & 0.427 & 487 & 1.04 & $(0.84,1.30)$ & 0.694 \\
\hline 6 months & 363 & 1.15 & $(0.93,1.42)$ & 0.205 & 537 & 0.91 & $(0.74,1.12)$ & 0.390 & 503 & 1.05 & $(0.86,1.28)$ & 0.654 \\
\hline 1 year & 363 & 1.22 & $(1.00,1.49)$ & 0.050 & 537 & 0.97 & $(0.80,1.18)$ & 0.795 & 503 & 1.06 & $(0.87,1.28)$ & 0.557 \\
\hline 4 years $^{\mathrm{d}}$ & 320 & 1.01 & $(0.80,1.27)$ & 0.934 & 456 & 0.86 & $(0.69,1.08)$ & 0.191 & 427 & 1.32 & $(1.06,1.65)$ & 0.012 \\
\hline First follow-upe & 358 & 0.95 & $(0.79,1.15)$ & 0.612 & 562 & 0.87 & $(0.73,1.04)$ & 0.126 & 527 & 1.11 & $(0.93,1.33)$ & 0.225 \\
\hline Second follow-up & 354 & 0.96 & $(0.79,1.17)$ & 0.680 & & & & N.A. & & & & N.A. \\
\hline \multicolumn{13}{|l|}{ Physical activity } \\
\hline At 3-6 years ${ }^{f}$ & 320 & & & 0.039 & 456 & & & 0.157 & 427 & & & 0.519 \\
\hline Normal & 192 & 1.00 & Reference & & 277 & 1.00 & Reference & & 259 & 1.00 & Reference & \\
\hline Low & 40 & 2.36 & $(1.15,4.81)$ & & 57 & 1.60 & $(0.83,3.09)$ & & 57 & 1.30 & $(0.65,2.61)$ & \\
\hline High & 88 & 0.90 & $(0.50,1.61)$ & & 122 & 0.77 & $(0.44,1.35)$ & & 111 & 1.34 & $(0.78,2.30)$ & \\
\hline At $6-10$ years $^{9}$ & 358 & & & 0.773 & 562 & & & 0.126 & 527 & & & 0.033 \\
\hline Normal & 234 & 1.00 & Reference & & 353 & 1.00 & Reference & & 333 & 1.00 & Reference & \\
\hline Low & 57 & 1.05 & $(0.57,1.96)$ & & 93 & 1.67 & $(0.97,2.87)$ & & 89 & 1.49 & $(0.87,2.56)$ & \\
\hline High & 67 & 0.82 & $(0.45,1.49)$ & & 116 & 1.15 & $(0.68,1.93)$ & & 105 & 1.94 & $(1.16,3.24)$ & \\
\hline
\end{tabular}

First follow-up: 10.8 years (girls) and 11.8 years (boys); Second follow-up: 12.8 years (both sexes)

Italics numbers indicate statistically significant results

$n$ number of participants, $O R$ odds ratio, $C l$ confidence interval, $L R$ - $p$ (likelihood ratio-test $\mathrm{p}$-value) refers to predictor only, $B M I \mathrm{lbody}$ mass index $\left(\mathrm{kg} / \mathrm{m}^{2}\right), S D S$ standard deviation score, N.A. not applicable

a Adjusted for sex, preeclampsia and gestational age

${ }^{b} \mathrm{n}=388$. Ordinal response: none, low grade, high grade (sum of specific $\lg \mathrm{E} \geq 3.9 \mathrm{kU} / \mathrm{l}$; above the lower quartile of all children being sensitized)

c Adjusted for sex, mother's asthma and mother's smoking

d Also adjusted for physical activity at 3-6 years

e Also adjusted for physical activity at 6-10 years

f Also adjusted for BMI SDS at 4 years

g Also adjusted for BMI SDS at the first follow-up

low physical activity during childhood was differentially associated with atopic sensitization, atopic dermatitis and asthma assessed in late childhood. BMI and physical activity were not associated with allergic rhinoconjunctivitis.

\section{Anthropometrics and outcomes}

In this cohort BMI at 1 year was positively associated with atopic sensitization at 12.8 years with borderline significance. As recently reviewed by Boulet [5], some studies are consistent with and others conflict our results, which may be due to differences in the study design. Studies showing an association have been cross-sectional and therefore unable to assess whether obesity precedes sensitization [5]. In our study, the majority of children were sensitized to airborne allergens. Sensitization to airborne allergens is uncommon in Scandinavian children before the age of 1 year [22]. It is therefore probable that the high BMI at 1 year preceded airborne sensitization. However, sensitization to food allergens may have been present in the first year of life, which we did not assess. In mice, obesity lowered the threshold for atopic sensitization, suggesting that obesity causes atopy [23].

Several mechanisms explaining the association between obesity and atopic sensitization have been suggested [5]. In addition to hormonal and genetic factors, a high BMI is associated with higher body fat and altered adipokines, and in turn might predispose to atopic sensitization through inflammatory changes [24]. Our results could indicate that a high BMI at the age of 1 year is of importance. 
Table 3 The adjusted odds ratios of atopic sensitization and atopic disease in adolescence in 617 Norwegian children by changes in weight/BMI SDS after backward stepwise selection of potential confounders (one model for each predictor variable)

\begin{tabular}{|c|c|c|c|c|c|c|c|c|c|c|c|c|}
\hline \multirow{3}{*}{$\begin{array}{l}\text { Predictor } \\
\text { Age }\end{array}$} & \multicolumn{12}{|c|}{ Outcome variable (final analyses) } \\
\hline & \multicolumn{4}{|c|}{ Atopic sensitization $^{\mathrm{a}, \mathrm{b}}$} & \multicolumn{4}{|c|}{ Allergic rhinoconjunctivitis ${ }^{a}$} & \multicolumn{4}{|c|}{ Atopic dermatitis $^{c}$} \\
\hline & $\mathrm{n}$ & OR & $95 \% \mathrm{Cl}$ & LR-p & $\mathbf{n}$ & OR & $95 \% \mathrm{Cl}$ & LR-p & $\mathbf{n}$ & OR & $95 \% \mathrm{Cl}$ & LR-p \\
\hline \multicolumn{13}{|l|}{ Weight SDS } \\
\hline Birth to 3 months & 361 & 1.10 & $(0.87,1.38)$ & 0.408 & 534 & 0.90 & $(0.74,1.09)$ & 0.292 & 500 & 0.98 & $(0.80,1.17)$ & 0.835 \\
\hline \multicolumn{13}{|l|}{ BMISDS } \\
\hline $3-6$ months & 351 & 1.15 & $(0.83,1.60)$ & 0.413 & 519 & 0.96 & $(0.71,1.30)$ & 0.794 & 485 & 1.15 & $(0.85,1.56)$ & 0.363 \\
\hline 6 months to 1 year & 360 & 1.30 & $(0.95,1.76)$ & 0.100 & 534 & 1.11 & $(0.83,1.48)$ & 0.470 & 500 & 1.07 & $(0.81,1.42)$ & 0.638 \\
\hline $1-4$ years & 325 & 0.82 & $(0.62,1.09)$ & 0.173 & 456 & 0.82 & $(0.63,1.07)$ & 0.150 & 427 & 1.46 & $(1.11,1.92)$ & 0.005 \\
\hline 4 years to first follow-up ${ }^{d}$ & 315 & 0.99 & $(0.78,1.26)$ & 0.940 & 450 & 1.01 & $(0.80,1.28)$ & 0.917 & 422 & 0.87 & $(0.70,1.09)$ & 0.223 \\
\hline First to second follow-up & 349 & 0.96 & $(0.65,1.43)$ & 0.843 & N.A. & N.A. & N.A. & N.A. & N.A. & N.A. & N.A. & N.A \\
\hline
\end{tabular}

First follow-up: 10.8 years (girls) and 11.8 years (boys); Second follow-up: 12.8 years (both sexes)

Italics numbers indicate statistically significant results

$n$ number of participants, $O R$ odds ratio, $C l$ confidence interval, $L R$ - $p$ likelihood ratio-test $\mathrm{p}$-value refers to predictor only, $B M I$ body mass index (kg/ $\mathrm{m}^{2}$ ), $S D S$ standard deviation score, N.A. not applicable

a Adjusted for sex, weight/BMI SDS at start of interval, gestational age, preeclampsia (none/mild or moderate/severe)

b $n=388$. Ordinal response: none, low grade, high grade (sum of specific lgE $\geq 3.9 \mathrm{kU} / \mathrm{l}$; above the lower quartile of all children being sensitized)

c Adjusted for sex, weight/BMI SDS at start of interval, mother's asthma and mother's smoking

d Also adjusted for physical activity at 3-6 years

e Also adjusted for physical activity at 6-10 years

In this cohort, change in BMI SDS from 1 to 4 years and BMI at 4 years were positively associated with atopic dermatitis ever at first follow-up. In the ISAAC 3 study, overweight and obesity at 13-14 years was associated with current atopic dermatitis [10]. In a meta-analysis, mainly of cross-sectional studies, a high BMI in childhood, adolescence and adulthood was also associated with atopic dermatitis [25].

Atopic dermatitis usually has its debut in the first years of life and normally precedes any potential overweight or obesity [7]. Therefore, there may be reverse causality, but it may also be possible that overweight/obesity causes atopic dermatitis. Firstly, obesity is associated with an increased risk of dry skin, aggravating underlying skin defects [26]. Secondly, the positive association of a change in BMI SDS and overweight in preschool years with atopic dermatitis could be explained by immunological changes due to increased body fat, and an association between adipokines and atopic dermatitis has been reported [27].

Anthropometric measures were not associated with allergic rhinoconjunctivitis in accordance with previous studies [28].

In the present study, there was no association between anthropometric measures during childhood and asthma in late childhood, without variation by sex. In 2013, six studies were included in a meta-analysis showing that overweight and obesity in childhood is associated with subsequent asthma. However, the results were inconsistent regarding sex [4]. Recently, in a study including $>24,000$ children, accelerated weight gain from birth to 3 years was positively associated with asthma by 3 years with risk ratio of 1.22 and at 7 years with risk ratio of 1.13 [9]. Our results do not contradict this, as we may have too few participants to show a significant association of a similar low magnitude.

\section{Physical activity and outcomes}

In this cohort, low preschool activity level was positively associated with atopic sensitization at 12.8 years. To our knowledge, this is the first study to show such an association. In a cross-sectional study of 2000 Spanish adolescents using questionnaires, there was no association between physical activity and allergy at 13-17 years [29].

In our study we adjusted for BMI, but BMI underestimates the relative amount of fat tissue in the body composition of children [30]. Thus, the association between low activity and atopic sensitization might be due to a higher body fat percentage in children with a low activity level, independent of weight status, with subsequent changes in adipokines that may influence the development of sensitization [24].

In this cohort, a high level of physical activity at 6-10 years was associated with atopic dermatitis ever at 
Table 4 The adjusted odds ratios of asthma in adolescence in 617 Norwegian children by weight/BMI SDS and physical activity after backward stepwise selection of potential confounders (one model for each predictor variable)

\begin{tabular}{|c|c|c|c|c|c|c|c|c|}
\hline \multirow{3}{*}{$\begin{array}{l}\text { Predictor } \\
\text { Age }\end{array}$} & \multicolumn{8}{|c|}{ Outcome variable (final analyses) } \\
\hline & \multicolumn{4}{|c|}{ Asthma ever by first follow-up ${ }^{a}$} & \multicolumn{4}{|c|}{ Current asthma at second follow-up } \\
\hline & $\mathbf{n}$ & OR & $95 \% \mathrm{Cl}$ & LR-p & n & OR & $95 \% \mathrm{Cl}$ & LR-p \\
\hline \multicolumn{9}{|l|}{ Weight SDS } \\
\hline Birth & 580 & 0.93 & $(0.72,1.20)$ & 0.587 & 439 & 0.95 & $(0.71,1.27)$ & 0.716 \\
\hline \multicolumn{9}{|l|}{ BMISDS } \\
\hline 3 months & 520 & 0.88 & $(0.64,1.21)$ & 0.437 & 411 & 0.96 & $(0.67,1.38)$ & 0.835 \\
\hline 6 months & 536 & 1.06 & $(0.79,1.41)$ & 0.707 & 425 & 0.86 & $(0.61,1.20)$ & 0.370 \\
\hline 1 year & 536 & 1.00 & $(0.76,1.32)$ & 0.998 & 424 & 0.78 & $(0.57,1.08)$ & 0.127 \\
\hline 4 years $^{c}$ & 454 & 1.09 & $(0.80,1.47)$ & 0.596 & 361 & 0.91 & $(0.63,1.32)$ & 0.627 \\
\hline First follow-up ${ }^{d}$ & 558 & 1.02 & $(0.79,1.33)$ & 0.849 & 426 & 1.10 & $(0.81,1.49)$ & 0.561 \\
\hline Second follow-up ${ }^{d}$ & N.A. & N.A. & N.A. & N.A. & 421 & 1.25 & $(0.90,1.72)$ & 0.176 \\
\hline \multicolumn{9}{|l|}{ Physical activity } \\
\hline At 3-6 years ${ }^{e}$ & 454 & & & 0.014 & 361 & & & 0.475 \\
\hline Normal & 275 & 1.00 & Reference & & 220 & 1.00 & Reference & \\
\hline Low & 57 & 3.61 & $(1.56,8.36)$ & & 48 & 1.92 & $(0.66,5.59)$ & \\
\hline High & 122 & 1.34 & $(0.61,2.97)$ & & 93 & 1.40 & $(0.55,3.55)$ & \\
\hline At 6-10 years ${ }^{f}$ & 558 & & & 0.038 & 426 & & & 0.177 \\
\hline Normal & 351 & 1.00 & Reference & & 274 & 1.00 & Reference & \\
\hline Low & 92 & 2.52 & $(1.24,5.12)$ & & 69 & 1.98 & $(0.80,4.85)$ & \\
\hline High & 115 & 1.02 & $(0.46,2.28)$ & & 83 & 1.97 & $(0.83,4.67)$ & \\
\hline
\end{tabular}

First follow-up: 10.8 years (girls) and 11.8 years (boys); Second follow-up: 12.8 years (both sexes)

Italics numbers indicate statistically significant results

$n$ number of participants, OR Odds ratio, $C l$ confidence interval, $L R$ - $p$ likelihood ratio-test $\mathrm{p}$-value refers to predictor only, $B M I$ body mass index ( $\mathrm{kg} / \mathrm{m}^{2}$ ), $S D S$ standard deviation score, N.A. not applicable

a After stepwise backward selection, adjusted for sex, gestational age, mother's preeclampsia and asthma

b After stepwise backward selection, adjusted for sex, mother's preeclampsia and mother's asthma

c Also adjusted for physical activity at 3-6 years

d Also adjusted for physical activity at 6-10 years

e Also adjusted for BMI SDS at 4 years

f Also adjusted for BMISDS at the first follow-up

first follow-up. This is in accordance with the findings in ISAAC 3, where vigorous physical activity in children 13-14 years was associated with current atopic dermatitis, and was attributed to sweat-induced itch [10]. One possible explanation for an association is that after long-term physical activity, natural killer cell cytotoxicity could be increased, which in turn has been associated with atopic dermatitis [31, 32].

We report an association of low physical activity at both 3-6 and 6-10 years with asthma ever, but not current asthma, in late childhood. In the ISAAC 3 study, several hours of TV viewing was associated with symptoms of current asthma in adolescents [10]. Similarly, studies indicate that physical activity could be protective against the development of asthma [11]. We found no association between physical activity and allergic rhinoconjunctivitis. In ISAAC 3, both associations of vigorous physical activity and a sedentary lifestyle at 13 years with allergic rhinoconjunctivitis were found with odds ratios at 1.25 and 1.17, respectively [10]. With the low number of participants in our study, our results do not contradict these results.

\section{Strengths and limitations}

Strengths: The study population is homogeneous regarding socio-economic status and ethnicity. Further, the predictor variables have been sampled by repeated measurements from several ages to examine the window of time in childhood the predictors could possibly affect the development of atopic sensitization and atopic diseases.

However, the study also has some limitations. The present study was not primarily designed to answer the current research questions, but this has been accounted for by including the design variable preeclampsia as a potential confounder, and no confounding was present. BMI may 
have limited correlation with childhood adiposity [3], and we did not have other adiposity measurements available from the visits at the well-baby clinics. Children who participated in the first follow-up but not in the second follow-up had a higher BMI and more atopic dermatitis. This may have biased our results, as both overweight and atopic dermatitis may be associated with atopic sensitization and other atopic disease. Only the predictors and not the outcomes were measured longitudinally, thus we cannot know if the associations reveal causality, or the direction of the causality. Lastly, due to several statistical analyses, the statistically significant results must be interpreted with care.

\section{Conclusions}

The results of this study suggest that BMI and physical activity in early childhood are associated with atopic sensitization, atopic dermatitis and asthma in later childhood. Larger cohorts with repeated measurements of both predictors and outcomes are needed to further elucidate this issue.

\section{Additional files}

Additional file 1: Figure S1. Directed Acyclic Graph. Colours of rings: Green $=$ predictor; blue with black dot $=$ outcome; blue $=$ ancestor of outcome; red = potential confounder; black = adjustment set; grey = unavailable/unknown confounders. Red line = biasing path; green line = causal path; black line $=$ closed path. The figure was made by using DAGitty software.

Additional file 2: Table $\mathbf{S 1}$. The adjusted odds ratios of asthma in adolescence in 617 Norwegian children by changes in weight/BMI SDS after backward stepwise selection of potential confounders (one model for each predictor variable). Table S2. The adjusted odds ratios of atopy in adolescence in 617 Norwegian children according to weight-related anthropometry in adolescence after backward stepwise selection of potential confounders (one model for each predictor variable).

\section{Abbreviations}

BMI: body mass index ( $\left.\mathrm{kg} / \mathrm{m}^{2}\right)$; IBM SPSS: International Business Machines Corporation Statistical Package for the Social Sciences; IgE: immunoglobulin E; ISAAC: International Study of Asthma and Allergies in Childhood; kU/l: kilo units per litre; MFPR: multiple fractional polynomial regression; SDS: standard deviation score.

\section{Authors' contributions}

MRF and KØ participated in the design of the study. KKB finalised the data collection and registration, performed all the statistical analyses and wrote a draft of the manuscript. GEE supervised the statistical analyses. PBJ supervised the planning and the drafting of the manuscript and contributed to the analyses of the data. $K \varnothing$ supervised all parts of the study and writing. All authors read and approved the final manuscript.

\footnotetext{
Author details

1 Department of Pediatrics, Stavanger University Hospital, POB 8100, 4068 Stavanger, Norway. ${ }^{2}$ Centre for Clinical Research, Haukeland University Hospital, Bergen, Norway. ${ }^{3}$ Department of Global Public Health and Primary Care, University of Bergen, Bergen, Norway. ${ }^{4}$ Department of Nutritional Sciences, School of Human Ecology, University of Texas at Austin, Austin, TX, USA.

${ }^{5}$ Department of Pediatrics, Haukeland University Hospital, Bergen, Norway.

${ }^{6}$ Department of Clinical Science, University of Bergen, Bergen, Norway.
}

\section{Acknowledgements}

This is a branch of the Stavanger Study at Stavanger University Hospital. We appreciate the important role of Bjørn Øglænd in the planning of the study and collection of data, and the help of paediatric nurses in the outpatient clinic at the department of paediatrics in collecting data. We would also like to thank participating mothers and children.

\section{Competing interests}

The authors declare that they have no competing interests.

\section{Availability of data and materials}

The database belongs to Stavanger University Hospital and cannot be shared unless a special agreement is made with Stavanger University Hospital, department of research.

\section{Ethics approval and consent to participate}

The study was approved by the Norwegian Data Inspectorate, the Regional Committee for Ethics in medical research Western Norway (Reference Numbers: First: 078-03, Second: 2010/1375), and the Institutional Review Boards of the National Cancer Institute and University of Texas at Austin, United States. Mothers and children signed an informed consent/assent form at follow-up.

\section{Funding}

"The Stavanger Study" was funded by an internal grant from the National Cancer Institute, $\mathrm{NIH}$ and is a part of the MD Anderson Global Programme. The present study was funded by a grant from the Western Norway Health Authority.

Received: 24 May 2016 Accepted: 1 August 2016

Published online: 24 August 2016

\section{References}

1. Ng M, Fleming T, Robinson M, Thomson B, Graetz N, Margono C, Mullany EC, Biryukov S, Abbafati C, Abera SF, et al. Global, regional, and national prevalence of overweight and obesity in children and adults during 1980-2013: a systematic analysis for the Global Burden of Disease Study 2013. Lancet. 2014;384(9945):766-81.

2. Schernhammer ES, Vutuc C, Waldhor T, Haidinger G. Time trends of the prevalence of asthma and allergic disease in Austrian children. Pediatr Allergy Immunol. 2008;19(2):125-31.

3. Guibas GV, Manios Y, Xepapadaki P, Moschonis G, Douladiris N, Mavrogianni C, Papadopoulos NG. The obesity-asthma link in different ages and the role of body mass index in its investigation: findings from the Genesis and Healthy Growth Studies. Allergy. 2013;68(10):1298-305.

4. Egan KB, Ettinger AS, Bracken MB. Childhood body mass index and subsequent physician-diagnosed asthma: a systematic review and metaanalysis of prospective cohort studies. BMC Pediatr. 2013;13:121.

5. Boulet LP. Obesity and atopy. Clin Exp Allergy. 2015;45(1):75-86.

6. Glavin K, Roelants M, Strand BH, Juliusson PB, Lie KK, Helseth S, Hovengen R. Important periods of weight development in childhood: a populationbased longitudinal study. BMC Public Health. 2014;14(1):160.

7. Eller E, Kjaer HF, Host A, Andersen KE, Bindslev-Jensen C. Development of atopic dermatitis in the DARC birth cohort. Pediatr Allergy Immunol. 2010;21(2 Pt 1):307-14.

8. Anderson EL, Fraser A, Martin RM, Kramer MS, Oken E, Patel R, Tilling K, Study P. Associations of postnatal growth with asthma and atopy: the PROBIT Study. Pediatr Allergy Immunol. 2013;24(2):122-30.

9. Magnus MC, Stigum H, Haberg SE, Nafstad P, London SJ, Nystad W. Peak weight and height velocity to age 36 months and asthma development: the Norwegian Mother and Child Cohort Study. PLoS One. 2015;10(1):e0116362.

10. Mitchell EA, Beasley R, Bjorksten B, Crane J, Garcia-Marcos L, Keil U, Group IPTS. The association between BMI, vigorous physical activity and television viewing and the risk of symptoms of asthma, rhinoconjunctivitis and eczema in children and adolescents: ISAAC Phase Three. Clin Exp Allergy. 2013;43(1):73-84.

11. Eijkemans M, Mommers M, Draaisma JM, Thijs C, Prins MH. Physical activity and asthma: a systematic review and meta-analysis. PLoS One. 2012;7(12):e50775. 
12. Ogland B, Vatten LJ, Romundstad PR, Nilsen ST, Forman MR. Pubertal anthropometry in sons and daughters of women with preeclamptic or normotensive pregnancies. Arch Dis Child. 2009;94(11):855-9.

13. Byberg KK, Ogland B, Eide GE, Oymar K. Birth after preeclamptic pregnancies: association with allergic sensitization and allergic rhinoconjunctivitis in late childhood; a historically matched cohort study. BMC Pediatr. 2014;14(1):101.

14. Worldwide variation in prevalence of symptoms of asthma, allergic rhinoconjunctivitis, and atopic eczema: ISAAC. The International Study of Asthma and Allergies in Childhood (ISAAC) Steering Committee. Lancet 1998:351(9111):1225-32.

15. Taylor-Piliae RE, Fair JM, Haskell WL, Varady AN, Iribarren C, Hlatky MA, Go AS, Fortmann SP. Validation of the Stanford Brief Activity Survey: examining psychological factors and physical activity levels in older adults. J Phys Act Health. 2010;7(1):87-94.

16. Alsnes IV, Janszky I, Forman MR, Vatten $\sqcup$, Okland I. A population-based study of associations between preeclampsia and later cardiovascular risk factors. Am J Obstet Gynecol. 2014;211(6):657.e1-7.

17. Textor J, Hardt J, Knuppel S. DAGitty: a graphical tool for analyzing causal diagrams. Epidemiology. 2011;22(5):745

18. Niklasson A, Albertsson-Wikland K. Continuous growth reference from 24th week of gestation to 24 months by gender. BMC Pediatr. 2008:8:8.

19. Juliusson PB, Roelants M, Nordal E, Furevik L, Eide GE, Moster D, Hauspie R, Bjerknes R. Growth references for 0-19 year-old Norwegian children for length/height, weight, body mass index and head circumference. Ann Hum Biol. 2013;40(3):220-7.

20. Brannsether B, Roelants M, Bjerknes R, Juliusson PB. Waist circumference and waist-to-height ratio in Norwegian children 4-18 years of age: reference values and cut-off levels. Acta Paediatr. 2011;100(12):1576-82.

21. Brannsether B, Roelants M, Bjerknes R, Juliusson PB. References and cutoffs for triceps and subscapular skinfolds in Norwegian children 4-16 years of age. Eur J Clin Nutr. 2013;67(9):928-33.

22. Nissen SP, Kjaer HF, Host A, Nielsen J, Halken S. The natural course of sensitization and allergic diseases from childhood to adulthood. Pediatr Allergy Immunol. 2013;24(6):549-55
23. Dietze J, Bocking C, Heverhagen JT, Voelker MN, Renz H. Obesity lowers the threshold of allergic sensitization and augments airway eosinophilia in a mouse model of asthma. Allergy. 2012;67(12):1519-29.

24. Nagel G, Koenig W, Rapp K, Wabitsch M, Zoellner I, Weiland SK. Associations of adipokines with asthma, rhinoconjunctivitis, and eczema in German schoolchildren. Pediatr Allergy Immunol. 2009;20(1):81-8.

25. Zhang A, Silverberg J. Association of atopic dermatitis with being overweight and obese: a systematic review and metaanalysis. J Am Acad Dermatol. 2015;72(4):606-16.e4.

26. Nino M, Franzese A, Ruggiero Perrino N, Balato N. The effect of obesity on skin disease and epidermal permeability barrier status in children. Pediatr Dermatol. 2012;29(5):567-70.

27. Machura E, Szczepanska M, Ziora K, Ziora D, Swietochowska E, BarcCzarnecka M, Kasperska-Zajac A. Evaluation of adipokines: apelin, visfatin, and resistin in children with atopic dermatitis. Mediators Inflamm. 2013;2013:760691.

28. Wang R, Custovic A, Simpson A, Belgrave DC, Lowe LA, Murray CS. Differing associations of BMI and body fat with asthma and lung function in children. Pediatr Pulmonol. 2014;49(11):1049-57.

29. Nova E, Martinez-Gomez D, Gomez-Martinez S, Veses AM, Calle ME, Veiga $\mathrm{OL}$, Marcos A. Influence of health behaviours on the incidence of infection and allergy in adolescents: the AFINOS cross-sectional study. BMC Public Health. 2014;14:19.

30. Brannsether B, Eide GE, Roelants M, Bjerknes R, Juliusson PB. Interrelationships between anthropometric variables and overweight in childhood and adolescence. Am J Hum Biol. 2014;26(4):502-10.

31. Del Giacco SR, Scorcu M, Argiolas F, Firinu D, Del Giacco GS. Exercise training, lymphocyte subsets and their cytokines production: experience of an Italian professional football team and their impact on allergy. BioMed Res Int. 2014;2014:429248.

32. Luci C, Gaudy-Marqueste C, Rouzaire P, Audonnet S, Cognet C, Hennino A, Nicolas JF, Grob JJ, Tomasello E. Peripheral natural killer cells exhibit qualitative and quantitative changes in patients with psoriasis and atopic dermatitis. Br J Dermatol. 2012;166(4):789-96.

\section{Submit your next manuscript to BioMed Central and we will help you at every step:}

- We accept pre-submission inquiries

- Our selector tool helps you to find the most relevant journal

- We provide round the clock customer support

- Convenient online submission

- Thorough peer review

- Inclusion in PubMed and all major indexing services

- Maximum visibility for your research

Submit your manuscript at www.biomedcentral.com/submit
() Biomed Central 